\title{
UTILIZAÇÃO DE RESÍDUOS POLIMÉRICOS DA INDÚSTRIA DE RECICLAGEM DE PLÁSTICO EM BLOCOS DE CONCRETO
}

\author{
Danilo Charbel Mattar ${ }^{1}$, Ednilson Viana ${ }^{2}$ \\ ${ }^{1}$ Gestor Ambiental pela Universidade de São Paulo - Escola de Artes, Ciências e Humanidades \\ ${ }^{2}$ Doutor em Engenharia Sanitária pela USP/São Carlos e professor no curso de Gestão Ambiental da Universidade de \\ São Paulo - EACH
}

http://dx.doi.org/10.5902/223611706471

\section{RESUMO}

O destino de resíduos poliméricos para outras finalidades que não sejam os aterros sanitários, como a utilização em blocos de concreto, caracteriza-se como uma importante medida de valorização de resíduos sólidos e redução do desperdício de matéria prima. Desta forma, este trabalho teve como objetivo central analisar a viabilidade técnica da utilização dos resíduos poliméricos irrecuperáveis de indústrias do segmento de plástico na produção de blocos de concreto. Para alcançar esse objetivo o material foi moído na empresa geradora dos plásticos em estudo e enviado para a produção dos blocos de concreto em empresa especializada no ramo. Logo após, o bloco seguiu para os testes de Resistência a Compressão, Verificação superficial, Analise dimensional, Absorção de água e Lixiviação. Realizados os testes, observou-se que só foram aprovados os tijolos com $5 \%$ de plástico, os quais não apresentaram qualquer problema de estrutura e, portanto, conclui-se como a porcentagem ideal de incorporação deste tipo de material em blocos de concreto.

Palavras chave: Resíduos Sólidos; Blocos de concreto; Polímeros.

\section{ABSTRACT}

The fate of polymeric wastes for purposes other than those landfills, such as use in concrete blocks, is characterized as an important measure of recovery of solid waste and reducing waste of raw materials. Thus, this study was aimed to analyze the technical feasibility of using waste polymeric stranded segment of plastic industries in the production of concrete blocks. To achieve this goal, the material was ground in generating company in the plastics and sent to study the production of concrete blocks in company specializing in the business. Soon after, the block went for tests of Compressive Strength, Verification surface, dimensional analysis, Water absorption and leaching. Performed tests, it was observed that only approved the bricks with $5 \%$ plastic, which did not present any problem structure and therefore concluded ideal as the percentage of incorporation of such material into concrete blocks.

Keywords: Solid Waste, Concrete blocks; Polymers

\section{INTRODUÇÃO}

Por definição, plásticos são substâncias sintéticas que copiam estruturas químicas encontradas na natureza. Além disso, eles também podem ser chamados de polímeros, palavra que tem origem grega onde poli significa muitos e meros, partes. Polímeros nada mais são do que a união de cadeias menores, denominadas monômeros, formando assim grandes moléculas com uma força de interação relativamente fraca em comparação com as forças de interação entre um 
Rev. Elet. em Gestão, Educação e Tecnologia Ambiental (e-ISSN: 2236-1170)

monômero (PARENTE, 2006).

O primeiro plástico que teve um processo verdadeiramente comercial foi o nitrato celulósico, e isso se deveu a John Hyatt de Albany, em Nova York no ano de 1863. Hyatt estudou sobre o nitrato celulósico descoberto por Alexandre Parkes, que por sua vez constatou que com a combinação de piroxilina e cânfora obtinha-se um material parecido com o marfim. Depois da obtenção deste material, que foi nomeado de celulóide, Hyatt conseguiu, através de temperatura e pressão, obter uma bola de bilhar. Esse fato teve uma grande importância na história do plástico, por que somente quarenta anos depois outro material foi descoberto, denominado baquelita (PARENTE, 2006).

Após esta descoberta vieram outras, como o monômero do PVC, cloreto de vanila e também o processo de vulcanização da borracha natural, através da adição de enxofre, descoberto por Goodyear. Somente em 1922, o alemão, Hermann Staudinger, conseguiu sintetizar a borracha em laboratório.

Os plásticos possuem propriedades específicas tais como leveza, resistência (há uma resistência ao impacto sem sofrer deformação), ataque a corrosão e a principal característica é a resistência a decomposição por microorganismos. Os plásticos também podem divididos em duas grandes categorias: os termoplásticos e os termofixos.

Os termoplásticos são materiais que podem ser aquecidos (derretidos) e resfriados sem perdas significativas de propriedades físicas, podendo ser solubilizados com solventes específicos. Entre os termoplásticos podemos citar o Polietileno (PE), Polipropileno (PP), Poliamidas (PA), Policarbonato (PC), Acrilinitrila Butadieno Estireno (ABS), Policloreto de Vanila (PVC), etc. Já os termofixos, também chamados de termorrígidos, são materiais que uma vez derretidos e conformados não é possível a sua recuperação, impedindo assim uma nova moldagem, ou seja, são materiais que não é possível a sua reciclagem. Um exemplo clássico é a baquelita, que são materiais usados em cabos de panelas, assim como outros como o Poliuretano (PU), Poliésteres (PS), etc (PIVA, 2004).

Em se tratando de reciclagem de plásticos, esta pode ser realizada de três formas distintas: a reciclagem física, a energética e a química.

A reciclagem física do plástico envolve um conjunto de etapas que são diferenciadas, dependendo da forma de obtenção do material e do processo empregado. Inicialmente o resíduo passa por uma triagem, onde são retirados materiais ferrosos por um sistema de imãs e não ferrosos por um sistema eletrostático. Posteriormente são retirados materiais leves como papel por ar comprimido e por último o material é conduzido a um tanque para separar as resinas por diferença de densidade. Esse material vai para um processo de trituração e lavagem, que irá retirar toda a sua impureza. Em seguida é retirada toda a umidade do material em estufas ou por aglutinador, dependendo do tipo de material que está sendo trabalhado (MANRICH, et al, 1997).

Por último, inicia-se o processo de extrusão, onde o material recebe temperatura e pressão. Com isso é possível a homogeneização e o melhor rearranjo das moléculas do polímero.

A reciclagem energética, por sua vez, corresponde a compactação dos resíduos e conseqüentemente a queima do material para a geração de energia. Este processo, porém, gera grandes quantidades de gases tóxicos para o meio ambiente, diminuindo a qualidade do ar nos locais onde estão instalados.

Outro tipo de reciclagem é a reciclagem química, que pode gerar tanto substâncias combustíveis como o retorno do resíduo na forma de monômero. A reação de polimerização de plástico é uma reação que aceita reversibilidade, isso é, pode ocorrer no sentido de formação do polímero ou para o retorno do monômero. O grande problema deste tipo de processamento está 
Rev. Elet. em Gestão, Educação e Tecnologia Ambiental (e-ISSN: 2236-1170)

associado ao custo energético e consequentemente econômico, para permitir a retomada do plástico a sua forma de monômero.

Na reciclagem física, especialmente, há uma fração de materiais plásticos oriundos das indústrias que não possui recuperação. São materiais não aprovados pelo processo de triagem e materiais contaminantes, quer dizer, materiais que a recicladora não possui nenhum interesse. Esses materiais podem ser destinados a incineração para a geração de energia, isto é, encaminhados para a reciclagem energética. Porém, esta não é uma boa solução para a sociedade por que os gases contaminantes podem gerar graves conseqüências para a saúde da população (MANRICH, et al, 1997). Neste aspecto, este trabalho busca contribuir explorando o uso de plásticos inservíveis de indústria de reciclagem de plásticos em blocos de concreto, permitindo a continuidade de uso destes plásticos de forma nobre.

\section{METODOLOGIA}

O material de estudo foi obtido junto a empresa R.F.D.- Plastic Indústria e Comércio de Plástico LDTA, com anuência já para o seu fornecimento e moagem. A empresa é especializada em reciclagem de resíduos plásticos, com ênfase na reciclagem de Poliamidas, com ou sem aditivos, como fibra de vidro, bissulfeto de molibdênio, talco, carbonato de cálcio, micro esfera de vidro, grafite, etc.

Os materiais utilizados neste trabalho foram plásticos irrecuperáveis, oriundos da limpeza das máquinas injetoras e/ou extrusoras, borras, galhos ou peças plásticas, que foram adicionados na massa do bloco de concreto, após moagem. Geralmente estes resíduos são os refugos do processo e não possuem mais viabilidade para a reciclagem, como varreduras que possuem contaminação com outros plásticos.

As etapas envolvidas neste trabalho forma as seguintes: Moagem; Homogeneização; Fabricação dos blocos; Análise dimensional; Verificação superficial; Absorção de água; Resistência a compressão; Lixiviação.

O processo de moagem permitiu a redução de granulometria dos materiais a aproximadamente $1 \mathrm{~cm}$ de diâmetro. Neste processo foi utilizado um moinho convencional de facas da marca Lvdao de plástico com 500 mm de diâmetro e com um motor de $11 \mathrm{Kw}$.

Após a moagem o material foi encaminhado para um homogenizador vertical com capacidade de 1 tonelada. E tanto esta etapa quanto a de moagem foram realizadas nas dependências da empresa R.F.D- Plastic Indústria e Comércio de Plásticos Ltda, geradora dos plásticos envolvidos neste estudo.

Feita a homogeinização do material, realizou-se a fabricação dos blocos de concreto na linha de produção da empresa Presto Pisos e Blocos de Concreto, onde obteve-se as amostras para a realização dos testes, realizados de acordo com o Quadro 1 e utilizando cimento, água, areia, pó de pedra, brita/pedrisco e o plástico irrecuperável. A inclusão deste tipo de plástico variou de $0 \%$ (padrão) até $25 \%$. 
Rev. Elet. em Gestão, Educação e Tecnologia Ambiental (e-ISSN: 2236-1170)

\begin{tabular}{|c|c|c|c|c|c|c|}
\hline & Cimento & Água & Areia & Pó de pedra & Brita / Pedrisco & Plástico \\
\hline Bloco 1 (Padrão) & $1 / 17$ & $6 \%$ & $27 \%$ & $53 \%$ & $20 \%$ & $0 \%$ \\
\hline Bloco 2 (5\%) & $1 / 17$ & $6 \%$ & $27 \%$ & $53 \%$ & $15 \%$ & $5 \%$ \\
\hline Bloco 3 (10\%) & $1 / 17$ & $6 \%$ & $27 \%$ & $53 \%$ & $10 \%$ & $10 \%$ \\
\hline Bloco 4 (15\%) & $1 / 17$ & $6 \%$ & $27 \%$ & $53 \%$ & $5 \%$ & $15 \%$ \\
\hline Bloco 5 (20\%) & $1 / 17$ & $6 \%$ & $27 \%$ & $53 \%$ & $0 \%$ & $20 \%$ \\
\hline Bloco 6 (25\%) & $1 / 17$ & $6 \%$ & $27 \%$ & $48 \%$ & $0 \%$ & $25 \%$ \\
\hline
\end{tabular}

Quadro 1 - composição dos blocos fabricados com os plásticos irrecuperáveis em função da porcentagem de cimento, água, areia, pó de areia e brita/pedrisco.

A empresa Presto Pisos e Blocos de Concreto utiliza bateladas com total de 1800 quilogramas. Porém, para tirar as amostras deste ensaio foram feitas bateladas de apenas 450 quilogramas, dividindo a quantidade inicial em quatro vezes para o efeito de análise e para evitar maiores desperdícios. Após a produção, os blocos com adição de sucata de plástico seguiram para a estufa onde foram retirados somente no dia seguinte.

Feita a produção dos blocos, iniciou-se a fase de testes para a sua possível aprovação ou reprovação mediante análises de qualidade.

A análise dimensional foi feita de acordo com a norma NBR 6136/2006. O teste consiste nas medições de largura, altura, comprimento, espessura longitudinal, espessura transversal, espessura equivalente, área bruta e mísula. Este procedimento foi realizado pela empresa Presto Pisos e Blocos de Concreto.

Os procedimentos do teste de verificação superficial foram os descritos pela norma NBR 6136/2006, que consiste em verificar a superfície do bloco, isso é, o bloco tem que atender alguns requisitos no que diz respeito a estética. A argamassa do bloco tem que estar distribuída de forma homogênea, compactada e não pode apresentar rachaduras significativas. Este teste também foi realizado pela empresa Presto Pisos e Blocos de Concreto.

O teste de absorção de água foi realizado de acordo com a norma NBR 6136/2006 e consiste em verificar o peso do bloco após um período de contato com a água, com pesagem antes e depois deste contato. Para este teste foi contratada uma empresa especializada para a realização do ensaio.

O teste de resistência a compressão verificou qual a influência exata do plástico no bloco de concreto. Assim como os outros testes, esse foi também realizado pela Presto Pisos e Blocos de Concreto e seguiu a norma NBR 6136/2006. O teste consiste em comprimir o bloco até a sua ruptura medindo a quantidade de $\mathrm{kg} / \mathrm{f}$ que será aplicado.

O teste de lixiviação foi feito em um laboratório especializado, a ABCP (Associação 
Rev. Elet. em Gestão, Educação e Tecnologia Ambiental (e-ISSN: 2236-1170)

Brasileira de Cimento Portland) onde foi analisado se o bloco com o plástico apresentou lixiviação de algum de seus componentes ou algum tipo de substância nociva ao meio ambiente ou ao seres humanos. Esses componentes testados foram: Prata, Arsênio, Bário, Cádmio, Cromo, Chumbo, Selênio, Mercúrio, Fluoreto e o pH.

\section{RESULTADOS E DISCUSSÃO}

O material obtido pelo processo de moagem apresentou uma granulometria esperada, com diâmetro de 1 (um) centímetro, granulometria esta que foi favorável a produção dos blocos de concreto. Por outro lado, houve certa dificuldade na trituração por que o material coletado da empresa apresentava formato muito heterogêneo, havendo desde partículas pequenas até materiais de grandes volumes (Figura 1).

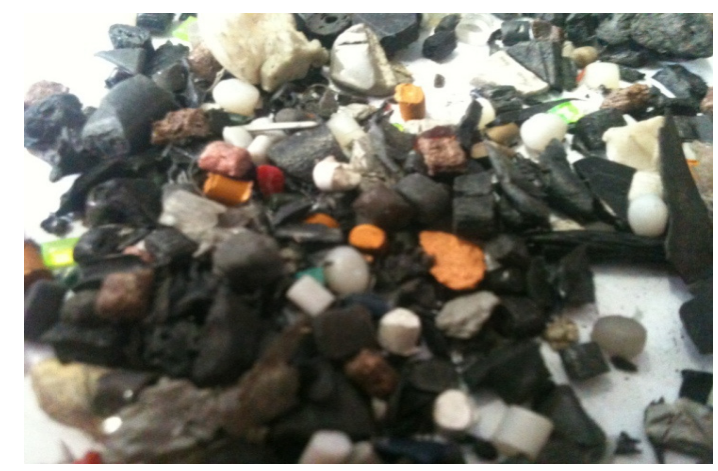

Figura 1 - Plástico irrecuperável gerado pela indústria de reciclagem de plástico, objeto deste estudo.

Após a homogeneização o material obtido apresentou uma coloração escura, de cor negra.

Os blocos obtidos com a adição de $5 \%$ de plástico não apresentaram qualquer problema, nem mesmo a necessidade de mudar alguma variável na máquina onde eles eram confeccionados. Por outro lado, alguns dos blocos confeccionados com $10 \%$ de polímeros apresentaram falhas como má formação das suas paredes. Mesmo assim foi possível retirar as amostras das formas. Após alguns ajustes na máquina, esse problema nas paredes dos blocos foi melhorada, porém não desapareceu.

A confeç̧ão de blocos com $15 \%$ de plástico foi inviável, pois logo após a moldagem na máquina os blocos se desfaziam, pelo fato da massa de concreto não ter se compactado de forma adequada. Isso pode ter ocorrido por que o plástico não contribuiu com a fixação dos outros materiais. Esta informação foi obtida com o responsável pela produção e qualidade da empresa Presto Pisos e Blocos de Concreto. Após esta etapa, os testes com inclusão de polímero acima de $10 \%$ foram canceladas, pois já estava evidente que os blocos não teriam integridade suficiente para desempenhar a sua função. O Anexo 1 mostra as quantidades exatas de materiais utilizados nas bateladas dos blocos.

A confecção de blocos com $15 \%$ de plástico foi inviável, pois logo após a moldagem na máquina os blocos se desfaziam devido a compactação inadequada da massa de concreto. Isso pode ter ocorrido por que o plástico não contribuiu com a fixação dos outros materiais. Esta informação foi obtida com o responsável pela produção e qualidade da empresa Presto Pisos e Blocos de Concreto. Após esta etapa, os testes com inclusão de polímero acima de $10 \%$ foram canceladas, pois já estava evidente que os blocos não teriam integridade suficiente para 
desempenhar a sua função. O Anexo 1 mostra as quantidades exatas de materiais utilizados nas bateladas dos blocos.

O teste de análise dimensional foi feito pela empresa Presto Pisos e Blocos de Concreto, e ambas as amostras foram aprovadas (Quadro 2 e 3). Não houve mudança significativa entre os blocos produzidos com $5 \%$ de plástico em relação aqueles produzidos com $10 \%$ de inclusão de plástico.

\begin{tabular}{|c|c|c|c|c|c|}
\hline & & & & & \\
\hline & Largura & Altura & Comprimento & Esp. Longitudinal & $\begin{array}{c}\text { Esp. } \\
\text { Transversal }\end{array}$ \\
\hline Medidas & 140 & 191 & 391 & 20 & 21 \\
\hline Tolerância & 2 & 3 & 3 & 1 & 1 \\
\hline Norma & 140 & 190 & 390 & 18 & 18 \\
\hline Resultado & Aprovado & Aprovado & Aprovado & Aprovado & Aprovado \\
\hline
\end{tabular}

Quadro 2 - médias das medidas em milímetros encontradas nos blocos de 5\% de plásticos após 14 dias da sua produção

\begin{tabular}{|c|c|c|c|c|c|}
\hline \multicolumn{6}{|c|}{ Medidas (mm) } \\
\hline & Largura & Altura & Comprimento & Esp. Longitudinal & $\begin{array}{c}\text { Esp. } \\
\text { Transversal }\end{array}$ \\
\hline Medidas & 141 & 191 & 391 & 20 & 21 \\
\hline Tolerância & 2 & 3 & 3 & 1 & 1 \\
\hline $\begin{array}{c}\text { Norma } \\
\text { Resultado }\end{array}$ & $\begin{array}{c}140 \\
\text { Aprovado }\end{array}$ & $\begin{array}{c}190 \\
\text { Aprovado }\end{array}$ & $\begin{array}{c}390 \\
\text { Aprovado }\end{array}$ & $\begin{array}{c}18 \\
\text { Aprovado }\end{array}$ & $\begin{array}{c}18 \\
\text { Aprovado }\end{array}$ \\
\hline
\end{tabular}

Quadro 3 - Médias das medidas em milímetros encontradas nos blocos de 10\% de plásticos após 14 dias da sua produção

A análise de verificação superficial mostrou que somente os blocos feitos com $5 \%$ de polímero foram aprovados, porém os blocos com 10\% (Figura 1), apresentaram rachaduras em sua parede, sendo aqui reprovados .Essa rachadura torna o bloco instável, pois pode com o passar do tempo se expandir podendo até ocorrer ruptura do bloco após utilização na obra. 


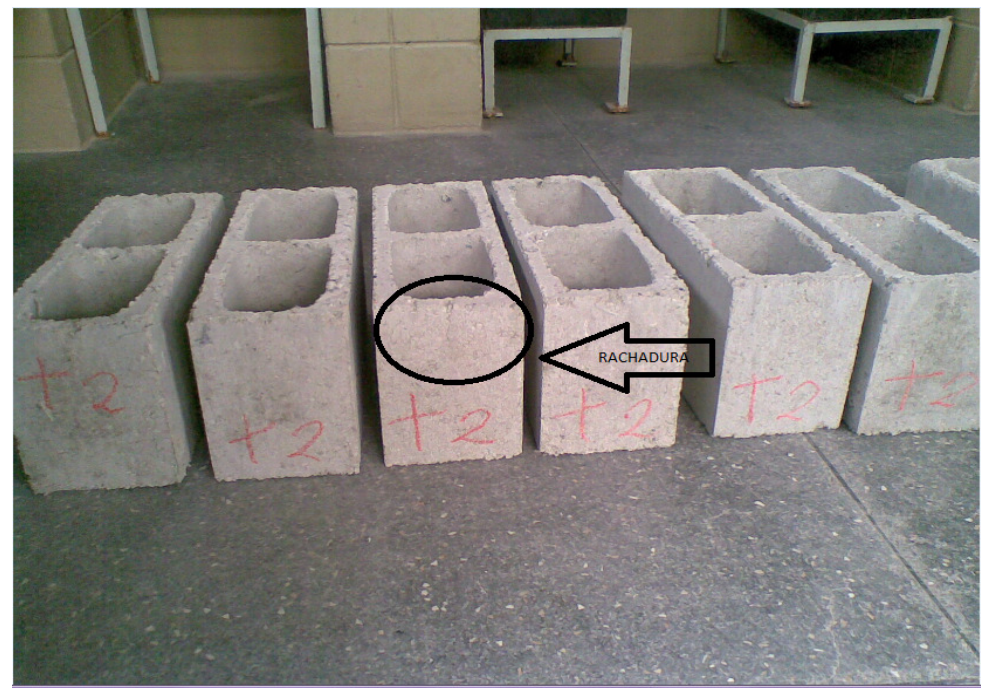

Figura 2 - Blocos confeccionados com 10\% de sucata de plástico e com rachaduras na sua estrutura.

O teste de absorção de água mostrou que ambos os blocos com $5 \%$ e $10 \%$ de adição de sucata de plástico foram aprovados de acordo com a norma NBR 6136/07, porém, nos blocos com $10 \%$ de plástico houve um pequeno aumento de absorção, ficando em 9,1\% (Quadro 4 e 5). Esse aumento de absorção de água não é benéfico para os blocos de concreto por causar acréscimos imprevistos de peso que podem prejudicar a sua durabilidade na parede saturada e causar possíveis danos nas paredes depois de construídos. Por isso a norma determina que a absorção de água deve ser menor do que $10 \%$.

\begin{tabular}{|c|c|c|c|c|c|}
\hline $\begin{array}{c}\text { Corpo de } \\
\text { prova }\end{array}$ & $\begin{array}{c}\text { Massa recebida } \\
\text { (g) }\end{array}$ & \multicolumn{2}{|c|}{ Absorção (\%) } & \multicolumn{2}{c|}{ Área líquida $\left(\mathrm{mm}^{2}\right)$} \\
\hline & & Individual & Média & Individual & Média \\
\hline 1 & 9255 & 8,5 & $\mathbf{8 , 4}$ & 24748 & $\mathbf{2 4 5 8 4}$ \\
\hline 2 & 9140 & 8,2 & & 24419 & \\
\hline
\end{tabular}

Quadro 4 - Teste de absorção de água para os blocos com $5 \%$ de sucata de plástico.

\begin{tabular}{|c|c|cc|c|c|}
\hline $\begin{array}{c}\text { Corpo de } \\
\text { prova }\end{array}$ & $\begin{array}{c}\text { Massa recebida } \\
(\mathrm{g})\end{array}$ & \multicolumn{2}{|c|}{ Absorção (\%) } & \multicolumn{2}{c|}{ Área líquida $\left(\mathrm{mm}^{2}\right)$} \\
\hline & & Individual & Média & Individual & Média \\
\hline 1 & 9029 & 9,1 & 9,1 & 25603 & 25004 \\
\hline 2 & 8613 & 9,1 & 24404 & \\
\hline
\end{tabular}

Quadro 5 - Resultado do teste de absorção de água para os blocos confeccionados com $10 \%$ de plástico

Quanto a resistência a compressão, os blocos feitos com $5 \%$ de polímero foram aprovados tanto no teste de 14 dias (Quadro 6) quanto no de 28 dias (Quadro 7) após a fabricação. 
Rev. Elet. em Gestão, Educação e Tecnologia Ambiental (e-ISSN: 2236-1170)

\begin{tabular}{|c|c|c|c|c|}
\cline { 2 - 5 } \multicolumn{1}{c|}{} & Massa & \multicolumn{2}{c|}{ Carga de ruptura } & Resistência \\
\hline Corpo de Prova & $(\mathrm{g})$ & $\left(\mathrm{kgf} / \mathrm{cm}^{2}\right)$ & $(\mathrm{N})$ & $(\mathrm{Mpa})$ \\
\hline 1 & 9245 & 19300 & 189.14 & 3,43 \\
\hline 2 & 9275 & 20300 & 198.94 & 3,63 \\
\hline 3 & 9100 & 20400 & 199.92 & 3,64 \\
\hline 4 & 9230 & 20700 & 202.86 & 3,71 \\
\hline 5 & 9445 & 20800 & 203.84 & 3,72 \\
\hline 6 & 9405 & 21600 & 211.68 & 3,84 \\
\hline Média & 9283 & 20516,67 & 201063,33 & 3,66 \\
\hline & & & fbk,est & 3,42 \\
\cline { 3 - 5 } & & & Requisito & 3 \\
\hline
\end{tabular}

Quadro 6 - Resultado do teste de compressão após 14 dias da fabricação do bloco com $5 \%$ de plástico que foi aprovado.

\begin{tabular}{|c|c|c|c|c|}
\cline { 2 - 5 } \multicolumn{1}{c|}{} & Massa & \multicolumn{2}{c|}{ Carga de ruptura } & Resistência \\
\hline Corpo de Prova & $(\mathrm{g})$ & $\left(\mathrm{kgf} / \mathrm{cm}^{2}\right)$ & $(\mathrm{N})$ & $(\mathrm{Mpa})$ \\
\hline 1 & 8870 & 20200 & 197.96 & 2,57 \\
\hline 2 & 8865 & 20600 & 201.88 & 3,64 \\
\hline 3 & 8910 & 20900 & 204.82 & 3,70 \\
\hline 4 & 8690 & 21100 & 206.78 & 3,73 \\
\hline 5 & 8760 & 21300 & 208.74 & 3,78 \\
\hline 6 & 8960 & 21600 & 211.68 & 3,83 \\
\hline Média & 8843 & 20950 & 205310 & 3,71 \\
\hline & & & fbk,est & 3,52 \\
\cline { 3 - 5 } & & & Requisito & 3 \\
\hline
\end{tabular}

Quadro 7 - Resultado do teste de compressão após 28 dias da fabricação do bloco com $5 \%$ de plástico que foi aprovado.

Os blocos feitos com $10 \%$ de polímero foram reprovados por não apresentarem a resistência adequada, ou seja, abaixo de $3 \mathrm{Mpa}$ (Mega Pascal) como mostra o Quadro 8. 
Rev. Elet. em Gestão, Educação e Tecnologia Ambiental (e-ISSN: 2236-1170)

\begin{tabular}{|c|c|c|c|c|}
\cline { 2 - 5 } \multicolumn{1}{c|}{} & Massa & \multicolumn{2}{c|}{ Carga de ruptura } & Resistência \\
\hline Corpo de Prova & $(\mathrm{g})$ & $\left(\mathrm{kgf} / \mathrm{cm}^{2}\right)$ & $(\mathrm{N})$ & $(\mathrm{Mpa})$ \\
\hline 1 & 8910 & 14300 & 140.14 & 2,56 \\
\hline 2 & 8830 & 15400 & 150.92 & 2,74 \\
\hline 3 & 8825 & 17300 & 169.54 & 3,08 \\
\hline 4 & 8555 & 17400 & 170.52 & 3,09 \\
\hline 5 & 8860 & 18000 & 176.4 & 3,22 \\
\hline 6 & 8970 & 18200 & 178.36 & 3,24 \\
\hline Média & 8825 & 16766,67 & 164313,33 & $\mathbf{2 , 9 9}$ \\
\hline & & & fbk,est & 2,22 \\
\cline { 4 - 5 } & & & Requisito & 3 \\
\cline { 3 - 5 } & & &
\end{tabular}

Quadro 8 - Resultado do teste de compressão dos blocos com 10\% de plástico

Percebe-se que há um aumento na resistência a compressão que o bloco suportou no teste de ruptura com 5\% de plástico após 14 e 28 dias de sua produção. Isso acontece por que as partículas dos blocos se acomodam e ficam mais compactadas.

Com relação ao teste de lixiviação, para todos os parâmetros os blocos ficaram dentro do permitido pela norma NBR 10004. A única mudança significativa do bloco de $5 \%$ de plástico para o bloco com $10 \%$ de plástico foi a concentração de fluoreto, mas mesmo assim a quantidade está dentro da norma de acordo com o Quadro 9.

\begin{tabular}{|c|c|c|c|c|c|}
\hline \multirow{2}{*}{ Constituinte } & \multicolumn{2}{|c|}{ Teor } & $\begin{array}{c}\text { Limite de Quantificação } \\
\text { (mg/L) }\end{array}$ & $\begin{array}{c}\text { NBR 10004 } \\
\text { (mg/L) }\end{array}$ \\
\cline { 2 - 6 } & 5\% de plástico & $10 \%$ de Plástico & 0,025 & 5,0 \\
\hline Prata & $(\mathrm{Ag})$ & N.D & N.D & 0,025 & 1,0 \\
\hline Arsênio & $(\mathrm{As})$ & N.D & N.D & 0,010 & 70,0 \\
\hline Bário & $(\mathrm{Ba})$ & 0,51 & 0,50 & 0,003 & 0,5 \\
\hline Cádmio & $(\mathrm{Cd})$ & N.D & N.D & 0,010 & 5,0 \\
\hline Cromo & $(\mathrm{Cr})$ & 0,22 & 0,20 & 0,025 & 1,0 \\
\hline Chumbo & $(\mathrm{Pb})$ & N.D & N.D & 0,025 & 1,0 \\
\hline Selênio & $(\mathrm{Se})$ & N.D & N.D & 0,0002 & 0,1 \\
\hline Mercúrio & $(\mathrm{Hg})$ & N.D & N.D & 0,02 & 150 \\
\hline Fluoreto & $\left(\mathrm{F}^{-}\right)$ & 3,22 & 3,74 & - & - \\
\hline pH & & 4,62 & 5,13 & \\
\hline
\end{tabular}

Quadro 9 - Resultado das quantidades de contaminantes encontradas nos blocos de concreto com $5 \%$ e com $10 \%$ de plástico. 
De acordo com todos os testes realizados, a quantidade ideal de adição de plástico é a de $5 \%$, isso por que nos testes de resistência a compressão e de verificação superficial o bloco com inclusão de $10 \%$ de polímero foi reprovado e os outros blocos, com $15 \%, 20 \%$ e copm $25 \%$ nem foi possível a sua produção. Essa quantidade de $5 \%$ de utilização de resíduos irrecuperáveis de plásticos no bloco é um ganho ambiental considerável para a sociedade, isso por que o material que teria que ser depositado nos aterros está sendo transformado em matéria prima para a construção civil, diminuindo assim a sobrecarga que os mesmos estão sofrendo. Para os Gestores Ambientais esta seria uma boa alternativa que aliviaria em longo prazo os problemas que o plástico ocasiona no processo de contaminação do solo, ainda mais o plástico que tem um tempo muito longo degradação na natureza.

As empresas geradoras de resíduos utilizam coletores de lixos especiais para retirar esses plásticos irrecuperáveis das suas organizações. Ao optarem pela utilização dos plásticos no bloco de concreto a empresa geradora do lixo teria um ganho financeiro, pois não necessitariam utilizar os serviços de empresas especializadas para a retirada das sucatas.

O preço para destinar este resíduo para um aterro está em torno de 120 reais por tonelada, porém, se for repassar este resíduo para as empresas fabricantes de bloco, este custo entre moagem e homogeneização, fica em torno de 300 reais a tonelada, tendo assim uma margem de 180 reais por tonelada.

Cabe agora as empresas fabricantes de blocos de concreto investirem em pesquisas futuras nesta área para saber se é viável financeiramente a utilização do plástico na confecção dos blocos, ou não. Esse cálculo teria que ser feito subtraindo-se o valor do metro cúbico do pedrisco e somando-se o valor que custaria o resíduo plástico moído.

Uma outra vantangem tanto para a empresa que optar em utilizar o plástico nos blocos de concreto quanto para a empresa que destinar esses plásticos para a indústria de blocos é que as empresas iriam assumir uma responsabilidade sócio-ambiental grande, isso por que esses resíduos não estaria sendo destinados nos aterros que fica por séculos e sem utilidade. Há uma certa variação dos tipos de resíduos que são destinados para a empresa de bloco de concreto, porém essas possíveis variações não irá prejudicar o processo de produção dos blocos, isso se manter o processo de homogeinização sempre como padrão do processo.

Seria importante que os governantes tomassem conhecimento da viabilidade da utilização do plástico irrecuperável na confecção dos blocos e incentivassem através de leis ou de benefícios fiscais as construtoras a utilizarem estes blocos. Este incentivo poderia de estendido também fabricante do bloco.

\section{Conclusões}

Conclui-se que há viabilidade técnica para a produção do bloco de concreto com plásticos irrecuperáveis, porém a quantidade que apresentou os melhores resultados foram os blocos do Teste 1 , com $5 \%$. Os blocos do Teste 1 ficaram dentro de todos os padrões esperados, não apresentando nenhuma diferença entre um bloco comum.

Os benefícios gerados utilizando $5 \%$ de plástico no bloco de concreto são de extrema 
importância para a sociedade pelo fato da diminuição da quantidade de resíduos que tem que ser depositados nos aterros diminuírem, e também pelo fato que essa alternativa irá gerar mais emprego e renda para toda a sociedade como um todo.

A utilização do bloco de concreto com resíduos irrecuperáveis da indústria é uma alternativa a mais que pode ser dada a esse tipo de resíduo, além de ser uma forma de ajudar a sociedade com o seu não descarte inadequado, como em ruas, calçadas, lixões em céu aberto, etc. Espera-se que com o tempo a sociedade crie um valor com esses resíduos e diminua significamente a quantidade descartada.

\section{RECOMENDAÇÕES FUTURAS}

-Refazer os testes com uma porcentagem diferente de quantidade de plástico. Uma sugestão seria fazer o teste com uma quantidade nas faixas $2 \%$ e de $10 \%$;

-Fazer uma análise financeira aprofundada da produção dos blocos e saber se há viabilidade econômica.

\section{REFERÊNCIAS}

-PIVA, A. M. Reciclagem de plástico. 2004. / Ana Magda Piva, Hélio Wiebeck. São Paulo: Artliber Editora, 2004.

-CAMPO, T. Logistica reversa: aplicação ao problema das embalagens da CEAGESP / Dissertação (Mestrado) - Escola Politécnica da Universidade de São Paulo. Departamento de Engenharia de Transporte. T, de Campos. -- São Paulo, 2006. 154p.

-JÚNIOR, A.C.L et al. Blocos de concreto para vedação: Estudo da conformidade através de ensaios laboratoriais. 2008. XXVIII Encontro Nacional de Engenharia de Produção. Rio de Janeiro, RJ, 2008 Disponível em: http://www.abepro.org.br/biblioteca/enegep2008 TN STO 073519 12236.pdf. Acesso em: $10 / 2010$.

-ASSOCIAÇÃO BRASILEIRA DE NORMAS TÉCNICAS (ABNT). NBR 6136: Bloco vazado de concreto simples para alvenaria estrutural - Requisitos. Rio de Janeiro, 2006.

-ASSOCIAÇÃO BRASILEIRA DE NORMAS TÉCNICAS (ABNT). NBR 12118: Bloco vazado de concreto simples para alvenaria estrutura - Método de ensaio: Análise dimensional e determinação da absorção de água, da resistência à compressão e da retração por secagem. Rio de Janeiro, 2006.

-INSTITUTO BRASILEIRO DE GEOGRAFIA E ESTATÍSTICA (IBGE). Comunicação social feita em 20 de Agosto de 2010. Disponível em: http://www.ibge.gov.br/home/presidencia/noticias/noticia_visualiza.php?id_noticia=1691\&id_pag ina=1 Acesso em: 11/2010.

-BRASIL. Lei $\mathrm{n}^{\circ} 12305$ de Agosto de 2010. Disponível em: http://www.planalto.gov.br/ccivil_03/_ato2007-2010/2010/lei//12305.htm. Acesso em: 11/2010 
-MANRICH, S. et al. Identificação de polímeros: uma ferramenta para a reciclagem. 1997. Universidade Federal de São Carlos. EDUFSCar - Editora da Universidade. São Carlos. 1997.

-MEDEIROS O. T. Alternativas de ultimação de Resíduos Plástico Termofixo. 2005. Universidade Federal do Rio Grande do Norte. Programa de pós-graduação em ciência e engenharia de materiais. Natal, 2005. Disponível em: ftp://ftp.ufrn.br/pub/biblioteca/ext/bdtd/OtonielMM.pdf. Acesso em: 11/2010.

-PARENTE R.A. Elementos estruturais de plástico reciclado. 2006. Universidade de São Carlos, USP. São Carlos, 2006. Disponível em: http://www.teses.usp.br/teses/disponiveis/18/18134/tde19072006-095941/pt-br.php. Acesso em: 11/2010

-SALVADOR. J. A. A. F. 5182b. Blocos de concreto para alvenaria em construções industrializadas. Universidade de São Carlos. São Carlos, 2007. Disponível em: http://www.teses.usp.br/teses/disponiveis/18/18134/tde-29012009-104204/pt-br.php. Acesso em $11 / 2010$

-PINTO, C.A. et al. Study of Mechanical Performance of Composites of Rubber Powder and Cement. Materials Science Forum Vols. 416-418. Switzerland, 2003.

-REVERSE LOGISTICS COUNCIL. Going Backwards: Reverse Loagistics Trends and Practices. 2004. Unversity of Nevada. Disponível em: http://www.rlec.org/reverse.pdf. Acesso em: 11/2010. 